\section{A contemporary reflection on Dr Gee's introduction to the first Medical Section meeting in 1907}

One hundred years ago, Dr Gee, President of the Medical Section of the newly formed Royal Society of Medicine, wrestled over the definition of 'medicine' and went on to consider this in relation to the structure of the Sections of the Society. He reflected that surgery had achieved equivalent status to medicine in the predecessor Medical and Chirurgical Society of London, expressed in terms that seem to leave little doubt about his own view that the purity of medicine had been to some extent affected, first by surgery, and later by other 'medical sects and societies too numerous to mention, which had committed such ravages on Medicine's garment ... '.

Dr Gee's address indicates that while there may have been issues of status and the relative importance of the different parts of medicine at that time, the underlying theme of concern in his introductory remarks to the Section of Medicine in 1907 is really to do with increasing specialization, and the consequent dangers of the fragmentation of medicine. He also bemoaned the fact that, in the process of formation of the new Royal Society of Medicine by incorporation of various different societies as Sections, there had been no attempt at rational classification (' . . . there was no fundamentum divisionis.'). He urged members of the Society to not lose sight of the universal aspect of medicine, that it remained 'primum inter pares'. His concern, it seems, was much greater than the mere nosology of the medical specialties.

Thus, at local level within the newly formed RSM in 1907, it was clearly recognized that the structure of the Sections had come about more by chance than through a process of planning, by simple amalgamation of a variety of willing medical societies based in London, to be joined by other societies over the next few years. One hundred years later, in 2007, a visitor to the RSM might reasonably ask about the logic of the current structure of the 55 existing Sections, some specialty based, others topic based. The answer, of course, is that Sections have arisen over the years in response either to advances in medicine and the resulting development of new clinical specialties (for example Palliative Care), or to new technologies (for example Radiology), or to wider cross-cutting subjects (for example Catastrophes and Conflicts, or Quality in Healthcare Forum). Over the years, some Sections have come and gone, for example Measurement in Medicine, its stated task achieved. Currently, other new Sections are about to be formed, in Critical Care and Pain Management, and we receive requests for additional new Sections on a regular basis, for example in Global Health and Medical Humanities, to name but two. Resources within the Academic Department limit the extent to which we can respond to these requests, rather than any resistance to new initiatives and ideas. The evolution of the Society, in response to advances in medicine and the changing national and international health care environment, must continue and is to be welcomed.

It is true that if starting with a blank sheet of paper, one would not design the structure of the Sections quite as one finds it today. But the diversity of interests and membership of the RSM, and the willingness of Sections to collaborate with each other and with external societies, the Medical Royal Colleges and many other organizations, is one of the great strengths of the Society today. The breadth of educational opportunity provided by the 400-odd meetings held annually by the Sections, by the Deans in the Society conference programme and increasingly in the Regions by the Regional Sub-Deans, is enormous.

From a less parochial viewpoint, it is fascinating to realize that specialization within medicine was a matter of such concern 100 years ago. Although not explicitly articulated by Dr Gee, his underlying concern must surely have been that because the great generalists and polymaths of medicine would be lost, the service offered to patients by the medical profession would suffer. Should we now continue to worry about doctors and other healthcare professionals training and practising in increasingly specialized areas? Will the advantages of higher standards of care for specific medical problems be outweighed by the inability of individuals, working in their specialized silos, to see the broader picture and thus miss conditions that are not within their narrow area of expertise? In short, is there a danger that medicine will become fragmented, to the detriment of patients?

May I be permitted the indulgence of offering some personal observations about the situation in 2007, assuming that I was preparing notes on the potential threat of increasing specialization, for a presentation to a similar captive audience as Dr Gee's?

The first point to emphasize is that no system of comprehensive primary care, as we know it today, existed in Dr Gee's time and access to health care must have been more haphazard, particularly for the less well-off in society. Despite some current concerns, most notably about the organization of out-of-hours services, the development of general practice remains one of the finest achievements of the NHS. General practitioners get to know their patients over long periods, they have an unrivalled opportunity to set illness in the context of individuals and their families, 
and they are in the best position to act as the gateway to secondary care in the great majority of cases. We need to resist any measure that leads to the fragmentation of primary care. This would, in my view, represent a fundamental threat to the very foundations of care within the NHS.

Second, although we have had to endure the recent mess of the Medical Training Application System (MTAS), one positive outcome has been the belated realization that all doctors require core training over a reasonable period before entry to specialist training. Many of us brought up in the 'old' system, benefitting from a good grounding in general medicine, have stubbornly held to this view all along. It is worth noting that in internal medicine alone, some 29 specialties are now recognized by the Royal Colleges of Physicians. A longer period of core training is better both for junior trainees, who gain greater general experience and have more time to make mature choices about their future careers, and of course for the patients they will treat when they become specialists. Furthermore, in internal medicine, a notable response to increasing specialization has been the emergence of the new specialty of Acute Medicine, staffed by doctors who are trained in the early management of all conditions presenting acutely. They can be seen as specialist generalists.

Third, it is impossible to halt the progress of medical science and its translation into health care, inevitably leading to the need for increasingly specialized practitioners. It would be foolish to expect that existing health services can stand still and simply absorb new developments without some degree of reorganization from time to time. This is not to advocate change for change's sake (and one recognizes that not all changes in the organization of the NHS in the recent past have been either popular or successful), but there is a need for adaptation and flexibility, however uncomfortable this may feel initially for those responsible on the front line of delivery of health care. It is surely possible to ensure that super-specialization in medicine is not accompanied by imbalance between specialties and divisive competition for resources, but rather that planning proceeds in an integrated fashion that always puts the needs of patients first, thus opposing the forces of fragmentation.

Fourth, in the post-Shipman era, the introduction of annual appraisal and the impending processes of recertification and revalidation should ensure that doctors remain competent to practise. Thankfully, a regulatory framework for doctors to demonstrate that they are keeping themselves up-to-date is now firmly in place. A major component of revalidation will be the formal demonstration by individuals that they have undertaken educational activities - Continuing Professional Development (CPD) — appropriate to their clinical practice. It is likely that the examination of an individual's CPD activities at annual appraisal will become increasingly detailed and searching. Doctors may become super-specialized, but if they wish to continue to practise as generalists they will need to demonstrate both that the CPD activities they undertake are appropriate and that they are competent to remain on the front line. While arrangements for CPD are now well advanced, regular assessment of an individual's competence to practise presents considerable challenges. We must expect - and welcome - the introduction of regular formal in-work and summative assessments for consultants in the next few years.

Dr Gee's concerns about the specialization and fragmentation of medicine are shared today and I predict will still be of importance in 2107. The RSM's role in contributing to health care in 2007 is essentially unchanged since 1907 - and indeed, since the formation of the Medical and Chirurgical Society of London in 1805: it is medical education, in its broadest sense.

\section{John Scadding}

Academic Dean, Royal Society of Medicine

email: john.scadding@rsm.ac.uk 